\title{
EFFECTS OF DEMOGRAPHIC FACTORS ON PROVISION OF FEEDBACK IN POSTGRADUATE MEDICAL EDUCATION
}

\author{
C. I. Bagwandeen* \\ Discipline of Public Health, School of Nursing and Public Health \\ e-mail: bagwandeenc@ukzn.ac.za
}

\section{S. Singaram*}

Clinical and Professional Practice, School of Clinical Medicine, e-mail: singaram@ukzn.ac.za

*College of Health Sciences

University of KwaZulu-Natal

Durban, South Africa

\section{ABSTRACT}

A key element in the process of clinical medical education is the process of providing feedback by comparing the directly observed performance of postgraduate doctors training to become specialists to that of a previously identified and communicated 'gold standard' and incorporating a plan for improvement. This is regarded as crucial to enhance clinical competencies. Hence, a greater understanding of the clinical educational environment and the various factors that impact on the giving and receiving of feedback within such a setting is required. A mixed methods approach was adopted for this observational study regarding the perceptions of the quality of feedback given and received at a large multicultural teaching hospital. Relationships between demographics and certain important aspects of the provision of feedback were observed which impact on the context in which feedback is given and received. The study found that appropriate strategies should be implemented to improve teaching capacity of consultants, together with gender empowerment and academic support programmes for registrars.

Keywords: Feedback, quality, registrars, consultants, demographics, clinical environment

\section{INTRODUCTION}

Within the ambit of clinical medical education, feedback on clinical performance of registrars - qualified doctors receiving advanced training in a specialist field of medicine - by consultants, or senior hospital-based physicians who have completed their specialist training, is regarded as crucial (Van de Ridder et al. 2008; Archer 2010). This process of comparing the directly observed performance of registrars to that of a previously identified and communicated 'gold standard' and incorporating a plan for improvement (Ende 1983) is a means to enhance the clinical competencies of registrars. Numerous studies on the provision and receiving of 
feedback report a discrepancy between registrars' and consultants' perceptions of the process. Registrars report that feedback is provided inadequately or not at all (Cantillion and Sargeant 2008; Boehler et al. 2006; Sender Liberman et al. 2005; Busari et al. 2005), while consultants are of the opinion that good quality feedback is provided often or always (Van de Ridder et al. 2008; Archer 2010; Sender-Lieberman et al. 2005). This disparity indicates that a greater understanding is required of the clinical educational environment and the various factors that impact on giving and receiving feedback within these settings.

Several contributing factors to this discrepancy have been described in the literature. One concerns the highly emotionally charged connotation associated with feedback, when registrars may rate feedback received as being of poor quality because of this, and not because this is actually so. Criticism, even if constructive - that is, given with the intent to improve performance - may be regarded as a 'negative' reflection of worth (Anderson 2012). Thus, any feedback opposing a registrar's self-assessment of their capabilities is rejected to protect their sense of worth (Jussim, Yen and Aiello 1995). However, self-assessment skills are often the poorest in those that are the least competent - the 'rookie' - and those who are the most confident, who tend to have an incorrectly overinflated sense of their abilities (Anderson 2012). Ironically, these are the groups that could most benefit from feedback. Thus, there is a barrier to accepting the validity of negative criticism, especially because the so-called 'Millennial Generation' has repeatedly been told how special they are (Bing-You and Trowbridge 2009). Although other studies support this view that registrars value praise over positive criticism (Boehler et al. 2006), this perceived dissatisfaction may also arise from the fact that registrars lack a clear operational definition of feedback (Van de Ridder et al. 2008) and, therefore, are unable to recognise feedback in its different forms when it is being provided (Branch and Paranjape 2002). Also, they may lack the maturational development to distinguish feedback from evaluation (Murdoch-Eaton and Sargeant 2012).

From another perspective, supervisors themselves may lack a framework within which to deliver feedback (Anderson 2012), may not possess the necessary capacity and training (BingYou and Trowbridge 2009; Ramani and Krackov 2012), or may be fearful of damaging students' self-esteem or endangering personal relationships that they have with their registrars and students (Cantillon and Sargeant 2008).

In addition to this, the operational demands of the clinical setting and heavy workloads may also play a role. Both consultants and registrars have to focus on service delivery rather than didactic teaching, and so learning becomes more an experiential rather a structured process of observation by a consultant with a view to improving the performance of the novice (Shrivastava, Shrivastava and Ramasamy 2014; Zehra et al. 2015; Daelmans et al. 2006). 
Broader contextual and environmental issues also impact on provision of feedback. Demographic factors such as race, gender, age and consultants' number of years' experience, and language differences can all influence the process (Shrivastava, Shrivastava and Ramasamy 2014; DeLima Thomas and Arnold 2011; Odom et al. 2007). Globally, race and ethnicity have been shown to affect medical schools in terms of admission criteria, pass rates, extension of probationary periods as well as hiring practices all along the continuum of university applicants, from residents to faculty (Odom et al. 2007; Kogan et al. 2012; Woolf, Potts and McManus 2011; Ferguson, James and Madeley 2002). Ruggs and Hebl (2012) report that students from diverse ethnic backgrounds in the United States of America feel so discriminated against that they are loathe to enter the Science, Technology, Engineering and Mathematic (STEM) fields. In South Africa, African, historically disadvantaged students report that the university environment is uncomfortable and exclusionary, and that they feel alienated from White students or those with a socio-economic advantage (Badat 2016; Badat 2009). Instead of their educational experiences becoming liberating and uplifting, these exact major psychological, emotional and academic tolls (Badat 2009).

Universities are striving to implement programmes to encourage diversity in staff and student populations and ensure their professional development and success (Odom et al. 2007; Cornell University 2010). However, it would appear that the effectiveness of such efforts is being called into question, as evidenced by increasing protest action of university students (Redden 2015). In 2015, and again in 2016, South African and American students mobilised around demands for free and fair tertiary education, with the \#FeesMustFall movement in South Africa and the \#MillionStudentMarch, where American students took to the streets making similar demands. This perceived militancy is in response to the barriers that previously disadvantaged undergraduate and postgraduate students at universities face on multiple fronts. These impediments may be lack of financial or social support, the negative self-image imposed upon them by virtue of their race, or being at a disadvantage because of the language of instruction, often not their home or first language (Odom et al. 2007; Rose, Rukstalis and Schuckit 2005; Ferguson, James and Madeley 2002; Shrivastava, Shrivastava and Ramasamy 2014). These protests were further extended into a call for true transformation of faculties, beyond only having representative numbers of ethnic minorities, with the demand for ‘decolonisation' and 'deracialism’ of the syllabus itself (Badat 2009).

Therefore, when looking at when and how feedback is delivered within the postgraduate setting, it must be noted that these barriers are factors that impact on feedback, for example, making it difficult for registrars to request it, especially because they may feel uneasy within the teaching spaces (Badat 2016). Further negatively impacting on how feedback can be given 
effectively, not only on clinical performance, but also, within the South African context, on making this information culturally relevant, is that most consultants have no formal teaching qualifications (Singh et al. 2013). Consideration should be given to how feedback information can be made culturally relevant in these contexts

With respect to the gender demographic factor, although female registrars are more likely to seek feedback (Sinclair and Cleland 2007; DeLima Thomas and Arnold 2011) compared to males, they are also more likely to report or experience discrimination. Odom et al. (2007) state that female registrars report often being mistaken for nurses. Conflicting evidence is provided by Lee et al. (2009) in a study of residents and academic performance, when they reported that males are more assertive in their communication styles and how they ask for feedback. However, in a systematic review of the literature on positive predictors for success in medical students, Ferguson, James and Madeley (2002) query the practical significance of examining such perceived differences, since significance is only reached in very large sample sizes. They argue that a more powerful factor should be developing intrinsic motivation of registrars, by instilling in them a love for learning that comes from within. This results in registrars seeking out feedback more actively in order to improve, rather than being externally motivated by the reward of good academic performance. However, in a study looking at the gender differences on how consultants provide feedback, male and female consultants did not appear to do this differently due to their gender (Singh et al. 2013).

With regard to the effect of age in the context of provision of feedback, younger registrars performed better academically than older registrars. This could be due to a greater time lapse between resuming clinical work again, or the greater personal responsibility of older registrars (Lee et al. 2009). However, age per se did not seem to effect feedback-seeking behaviour (Lee et al. 2009). Although, Wittich et al. (2012) found that registrars perceived older consultants to be better at providing feedback than their younger colleagues, perhaps because they equated experience with excellence. However, Kogan et al. (2012) report that faculty approaches to feedback are based rather on more contextual factors such as their own views on how effective they were at delivering feedback and relational issues, rather than age or experience alone. Academic trainees, i.e. junior doctors with an academic or research component in their training qualification, were also more likely to incorporate a plan for how registrars could improve into their feedback as compared to areas for improvement than consultants (Fernando et al. 2008).

In previous studies conducted by the authors in the same multicultural academic hospital as the current study, it was found that the majority of the registrars believed that the feedback was not given often enough, was of poor quality and was not based on concrete observations of performance (Bagwandeen and Singaram 2016b). This belief was borne out by the findings that 
only just over a third of the consultants communicated in advance the desired standards of performance to be obtained and only about $40 \%$ gave feedback always or often (Bagwandeen and Singaram 2016a). More importantly, these studies found that the registrars believed that the feedback provided was influenced by their race, gender and ethnicity. Hence, this study aims to explore further the relationship between race, gender, age, home language, discipline and year of study or specialisation and how this effects the provision and receiving of feedback by consultants and registrars, respectively.

\section{METHOD}

A mixed methods approach was adopted for this observational study, to enhance the quality of the quantitative data through the use of illustrative quotes (Creswell 2013). Perceptions regarding feedback were collected by means of a self-administered questionnaire given to both registrars and consultants at the hospital. The 23 open and closed-ended questions elicited information on feedback, specifically on its nature, how often it was given or received (frequency), its effect, when, where and how it was provided or received and the its type. Other data was collected on demographic and some professional characteristics relating to age, gender, home language, discipline and years of training or specialisation. All 60 consultants and 60 registrars from the disciplines of Surgery, Internal Medicine, Obstetrics and Gynaecology, Paediatrics, Psychiatry and Family Medicine were invited to participate in the study.

Responses to the quality of feedback were reported on a 5-point Likert scale $(1=$ Never to $5=$ Always). Descriptive statistics were used to interpret the responses of the registrars and consultants, with mean values being calculated. Differences between groups were calculated using Pearson's Chi Square test for independent variables, with a $p$-value of $<0.05$ regarded as being statistically significant.

Responses to open-ended questions were read and re-read to ascertain familiarity with the data. Emergent themes and sub-themes were consensually identified by both authors. Relevant quotations were used to support and extend the quantitative data.

Full ethical approval for the study was received from the Humanities and Social Sciences Ethical Committee, University of KwaZulu-Natal (HSS/1185/013D).

\section{RESULTS}

Sixty-two percent $(n=37)$ of both consultants and registrars respectively consented to participate in the study anonymously. For ease of reference mostly statistically significant relationships are reported and responses of the participants are combined to give an overall negative (1, 2 and 3) 
and positive response (4 and 5) to certain questions.

\section{Demographic and professional characteristics of participants}

As illustrated in Table 1, consultants were on average 37.8 years old (range 31-55). The majority of consultants were Indian (27), female (20), had been consultants for less than five years (20) and spoke English as their first language (31). Thirteen consultants from Paediatrics, nine from Internal Medicine, eight from Obstetrics and Gynaecology, three from Surgery and two each from Psychiatry and Family Medicine, responded. Six consultants had qualifications other than the Fellowship, one consultant had a Doctorate of Philosophy, while the other five had postgraduate certificates in their respective fields.

Table 1: Demographic and professional characteristics of consultants

\begin{tabular}{|c|c|c|c|}
\hline & & $\mathbf{N}$ & (\%) \\
\hline \multirow[t]{4}{*}{ Age } & $<35$ & 13 & $(35.14)$ \\
\hline & $35-39$ & 14 & (37.84) \\
\hline & $40-44$ & 4 & $(10.81)$ \\
\hline & $>40$ & 6 & $(13.51)$ \\
\hline \multirow[t]{5}{*}{ Race } & Black & 4 & $(10.81)$ \\
\hline & White & 3 & (8.11) \\
\hline & Indian & 27 & (72.97) \\
\hline & Coloured & 3 & (8.11) \\
\hline & Other & 0 & $(0.00)$ \\
\hline \multirow[t]{2}{*}{ Gender } & Male & 17 & $(45.95)$ \\
\hline & Female & 20 & $(54.05)$ \\
\hline \multirow[t]{3}{*}{ Years of Specialisation } & $<5$ & 20 & $(55.56)$ \\
\hline & $5-9$ & 10 & $(27.78)$ \\
\hline & $>10$ & 6 & (16.67) \\
\hline \multirow[t]{6}{*}{ Discipline } & Surgery & 3 & (8.11) \\
\hline & Internal Medicine & 9 & $(24.32)$ \\
\hline & Obstetrics \& Gynaecology & 9 & $(24.32)$ \\
\hline & Paediatrics & 12 & $(32.43)$ \\
\hline & Psychiatry & 2 & $(5.41)$ \\
\hline & Family Medicine & 2 & (5.41) \\
\hline \multirow[t]{4}{*}{ Highest previous qualification obtained } & Fellowship & 31 & (83.78) \\
\hline & MMed & 0 & $(0.00)$ \\
\hline & PhD & 1 & $(2.70)$ \\
\hline & Other & 5 & $(13.51)$ \\
\hline \multirow[t]{5}{*}{ Home/First language } & English & 31 & $(83.78)$ \\
\hline & Afrikaans & 1 & $(2.70)$ \\
\hline & IsiZulu & 2 & (5.41) \\
\hline & IsiXhosa & 3 & (8.11) \\
\hline & Other & 0 & $(0.00)$ \\
\hline
\end{tabular}

As illustrated in Table 2, the mean age of registrars was 32.3 years (range 27-43). The majority 
of the registrars were Indian (20) and female (24). Most of the registrars (16) were in their fourth year of Registrar training, 12 were in their third year, seven were in their second year, and two had recently commenced training. The registrars' specialisations were divided as follows: Paediatrics (9), Obstetrics and Gynaecology (9), Surgery (7), Internal Medicine (6), Psychiatry (3) and Family Medicine (3). Only two of the registrars had a Postgraduate Diploma, one had a Masters in Medicine, while the remaining 34 had completed only their basic undergraduate medical degree. Twenty of them were first language English speakers and seventeen were second language English speakers.

Table 2: Demographic and professional characteristics of registrars

\begin{tabular}{|c|c|c|c|}
\hline & & $\mathbf{N}$ & (\%) \\
\hline \multirow[t]{5}{*}{ Age } & $<25$ & 1 & $(2.70)$ \\
\hline & $25-29$ & 5 & $(13.51)$ \\
\hline & $30-35$ & 25 & $(67.57)$ \\
\hline & $35-39$ & 4 & $(10.81)$ \\
\hline & $>40$ & 2 & $(5.41)$ \\
\hline \multirow[t]{5}{*}{ Race } & Black & 14 & $(37.84)$ \\
\hline & White & 2 & $(5.41)$ \\
\hline & Indian & 20 & $(54.1)$ \\
\hline & Coloured & 1 & $(2.70)$ \\
\hline & Other & 0 & $(0.00)$ \\
\hline \multirow[t]{2}{*}{ Gender } & Male & 13 & $(35.14)$ \\
\hline & Female & 24 & $(64.86)$ \\
\hline \multirow[t]{4}{*}{ Years of Specialisation } & $1^{\text {st }}$ & 2 & $(5.41)$ \\
\hline & $2^{\text {nd }}$ & 7 & $(18.92)$ \\
\hline & $3^{\text {rd }}$ & 12 & $(32.43)$ \\
\hline & $4^{\text {th }}$ & 16 & $(43.24)$ \\
\hline \multirow[t]{6}{*}{ Discipline } & Surgery & 7 & $(18.92)$ \\
\hline & Internal Medicine & 6 & $(16.22)$ \\
\hline & Obstetrics \& Gynaecology & 9 & $(24.32)$ \\
\hline & Paediatrics & 9 & $(24.32)$ \\
\hline & Psychiatry & 3 & $(8.11)$ \\
\hline & Family Medicine & 3 & $(8.11)$ \\
\hline \multirow[t]{3}{*}{ Highest previous qualification obtained } & MBChB & 34 & $(91.89)$ \\
\hline & MMed & 1 & $(2.70)$ \\
\hline & Other & 2 & $(5.41)$ \\
\hline \multirow[t]{12}{*}{ Home/First language } & English & 20 & $(54.05)$ \\
\hline & Afrikaans & 0 & $(0.00)$ \\
\hline & IsiZulu & 8 & $(21.62)$ \\
\hline & IsiXhosa & 1 & $(2.70)$ \\
\hline & siSwati & 1 & $(2.70)$ \\
\hline & Northern Sesotho & 1 & $(2.70)$ \\
\hline & Sesotho & 1 & $(2.70)$ \\
\hline & Setswana & 1 & $(2.70)$ \\
\hline & Xitsonga & 0 & $(0.00)$ \\
\hline & Tshivenda & 0 & $(0.00)$ \\
\hline & Southern isiNdebele & 0 & $(0.00)$ \\
\hline & Other & 4 & $(10.81)$ \\
\hline
\end{tabular}




\section{Relationship between gender and perceptions of the quality of feedback given by consultants and received by registrars}

Male consultants were significantly more likely than female consultants to rate their feedback sessions as always successful, with the registrars receiving the intended message in the intended manner $(\mathrm{p}<0.04)$. No other significant relationships were found between gender differences and consultant perceptions.

Male registrars felt significantly more strongly than females that feedback was based on concrete observations of their performance $(\mathrm{p}<0.00)$, was given in non-emotive and nonjudgmental language $(\mathrm{p}<0.02)$, was given about techniques performed incorrectly $(\mathrm{p}<0.00)$ and correctly $(\mathrm{p}<0.03)$ and was not influenced by race, gender or ethnicity $(\mathrm{p}<0.00)$. Positive perceptions about receiving feedback about certain specific skills, namely technical skills $(\mathrm{p}<0.03)$ and evidence-based practice $(\mathrm{p}<0.00)$, as well as desired graduate competencies - how to be a professional $(\mathrm{p}<0.04)$ - was also statistically significantly higher in male versus female registrars. Unlike females, male registrars were more confident that support was available from different sources after a feedback session $(\mathrm{p}<0.04)$. They felt more strongly that feedback sessions were always successful ( $p<0.01$ ), and would be happy to make use of the techniques used by their consultants when they had students in the future $(\mathrm{p}<0.01)$. Males agreed more with the feedback provided $(\mathrm{p}<0.03)$ than the female registrars.

Male registrars said that after feedback they felt, 'Positive. Used the critique in a constructive manner' and 'determined to improve and step up performance to perform better', while female registrars were more ambivalent, stating: 'According to situation. Happy if positive, sad if negative' and 'Sometimes belittled, sometimes encouraged'.

\section{Relationship between English first language (EFL) and English second language (ESL) speakers and perceptions of the quality of feedback given by consultants and received by registrars}

Consultants who were EFL speakers gave more feedback about specific desired graduate attributes, such as how to be a communicator $(\mathrm{p}<0.03)$ and a collaborator $(\mathrm{p}<0.01)$, than consultants who spoke English as a second language. Registrars who were ESL speakers reported statistically significantly more favourably that feedback was based on concrete observations of performance $(\mathrm{p}<0.02)$, was given about techniques performed incorrectly $(p<0.01)$, that a plan for improvement was incorporated into the process $(p<0.04)$, that feedback was not influenced by race, gender or ethnicity $(\mathrm{p}<0.02)$ and that feedback sessions were always successful $(\mathrm{p}<0.02)$ in comparison to registrars whose first language was English. The ESL group also gave better ratings regarding feedback given about specific technical skills $(\mathrm{p}<0.03)$, 
interpersonal skills $(\mathrm{p}<0.00)$, evidence-based practice $(\mathrm{p}<0.01)$ and ethics $(\mathrm{p}<0.03)$ than those with English as a first language.

With specific reference to these graduate attributes, EFL speaking consultants noted that they gave feedback in order to 'Improve their (registrars') learning and communication’ and to 'Help with their (registrars') personal and professional development'. The ESL registrars noted that they 'Had made some improvement in personal skills and communication' and 'Improved communication with patients'.

\section{Relationship between discipline and the perceptions of the quality of feedback given by consultants and received by registrars}

Surgical consultants were significantly more likely than consultants in the other disciplines to provide formal and informal feedback in all encounters with registrars $(\mathrm{p}<0.00)$, to schedule formal feedback sessions in advance $(\mathrm{p}<0.03)$, to determine standards to be obtained and communicate this in advance to the registrars $(\mathrm{p}<0.04)$ and provide feedback about procedures performed both incorrectly and correctly $(\mathrm{p}<0.00)$. For registrars, there was a statistically significant difference between the composite median scores across the disciplines $(p<0.00)$, with registrars in Surgery having the highest median perception score, reporting most favourably on the quality of the feedback received. Internal Medicine and Paediatrics had the lowest median overall score. However, no statistically significant difference was observed between disciplines in items relating to whether feedback encouraged reflection about previous feedback $(\mathrm{p}<0.11)$ or whether they would use these techniques with their own students in future $(\mathrm{p}<0.13)$.

Registrars reported that the General Surgery gave 'Excellent feedback on a regular basis’, 'had excellent consultants' and 'gave regular feedback on progress, with bedside and clinical teaching'.

\section{Relationship between year of study and perceptions of the quality of feedback of registrars given by consultants and received by registrars}

Registrars in their first year, as compared to registrars in subsequent years, believed more strongly that feedback was based on concrete observations of performance $(p<0.04)$, was given about techniques performed incorrectly $(\mathrm{p}<0.04)$, encouraged reflection about previous feedback $(\mathrm{p}<0.00)$, that it was documented $(\mathrm{p}<0.01)$, that support was available to them from different sources after feedback sessions $(\mathrm{p}<0.04)$ and that consultants were proficient at giving feedback $(p<0.03)$. First year registrars also had more positive responses as opposed to the senior registrars regarding receiving feedback about skills - both technical $(p<0.04)$ and ethical 
$(\mathrm{p}<0.04)$ - and on specific graduate attributes - how to be a medical expert $(\mathrm{p}<0.03)$, scholar $(\mathrm{p}<0.03)$ and professional $(\mathrm{p}<0.02)$.

Senior registrars felt that feedback, 'Doesn't happen often enough' and 'Should occur all through the programme'. They also noted work pressure and time constraints, stating, 'We are expected to be the workforce. No time to consolidate and read.'

\section{Relationship between age and experience and the perceptions of the quality of feedback given by consultants and received by registrars}

Age did not significantly influence the overall perceptions of the quality of feedback given or received for either consultants or registrars in this study. However, a positive relationship between composite perception score and age of consultant was observed, with the consultants perceiving that they gave better feedback as age increased $(\mathrm{p}<0.05)$. Conversely, there was a moderately negative relationship between composite perception score and age of registrar, with the score declining as age increased - the older registrars believed the quality of the feedback they received to be poorer compared to their younger counterparts.

Both consultants and registrars felt that the esteem that consultants were held in influenced how feedback was received and provided. Consultants commented that, 'Registrars are more receptive if they have respect for the person providing the feedback' and that 'Feedback from a junior consultant seems to hold less weight than from a senior consultant'. Registrars concurred, commenting that, 'Holding my consultant in high regard helps with the feedback as I value his opinion'.

\section{Relationship between race and the perceptions of the quality of feedback given by consultants and received by registrars}

With regard to consultants, Black consultants were not affected by the race, gender or ethnicity of the registrars when they gave feedback to them, as compared to consultants of other race groups $(\mathrm{p}<0.05)$. Indian consultants, unlike their African or White colleagues, gave significantly more specific feedback about how to be an effective communicator (a graduate competency outcome $)(\mathrm{p}<0.02)$, and reported more significantly that they were proficient at giving feedback to registrars $(\mathrm{p}<0.02)$. No statistically significant relationship was observed between any of the individual items and race groups for registrars.

Consultants noted, with respect to the effect of race on providing it, that feedback 'Improves learning and communication', and that 'It is important to remain unbiased and objective'. The benefits of feedback as a whole were noted by registrars and, regardless of race, they thought that 'Feedback was not personal, it is given in a constructive manner' and 
'Feedback by my consultants is always received in a good way'.

\section{DISCUSSION}

It is noted that students from previously disadvantaged backgrounds generally report feeling marginalized and exposed to conflict within academic settings (Badat 2016; Daniel 2007). The multicultural, heterogeneous setting of this medical school would indicate an increased need to understand the contextual factors, especially those of a demographic nature, that affect such students. A deeper understanding will allow for greater insight into exactly what the issues of importance are, be they a lack of cultural sensitivity, language barriers, latent racism or sexism, and allow for implementation of appropriate corrective measures to rectify the prevailing problems. At present, it would appear that the call for curriculum transformation underpin many of the factors identified as elemental in hindering feedback. Suellen Shay, Dean and Associate Professor of the University of Cape Town's Centre for Higher Education Development, writing in the Daily News section of the University's website on the $13^{\text {th }}$ of June 2016 , examined and synthesised the call for a revised curriculum, noting that transformation would engender a better 'fit', both in terms of the population that undergraduates are drawn from, as well as the better preparation of graduates for their future work world, be it in first, world hi-tech medicine or among rural poor. However, as Harry Garuba noted in a Mail and Guardian article on 27 February 2015, curricular reform needs to considered as more than just inserting certain items into an existing structure, but should be examined closely as to whether a complete overhaul is needed.

The effect of gender on the provision of feedback was noted in the perception of male consultants in this study that their feedback sessions were always successful. This may be due to the fact that the power differences that exist between the sexes, that is evident in general conversation can also lead to the disempowerment of women in supervision. Female consultants are more likely to defer to their male colleagues, and in turn their subordinates, as a result of their own training experiences (Davis and Allison 2013; Nelson and Holloway 1990). Despite being correct, women often do not assert their rightful position of being the expert. Male registrars felt overall that the feedback they received was of good quality as compared to females. They also felt strongly positive about different individual aspects, and that sessions were always successful - so strongly that they would use similar techniques with their own students. They reported feeling motivated to improve their performance, as compared to female registrars who reacted according to whether the feedback was perceived as positive or negative criticism. Although female gender has been generally cited as a predictor for success in more affluent Western communities (Ferguson, James and Madeley 2002), the subordinate position 
of women (Davis and Allison 2013; Nelson and Holloway 1990) can account for these statistically significant results of the more positive perceptions of male versus female registrars in reporting on their experience of feedback. While internationally the numbers of women entering the medical field are increasing, there is still a disparity in their representation throughout, as well as in the higher echelons of the profession (Kilminster et al. 2007) which may be attributed to their greater willingness to sacrifice their aspirations as compared to their male colleagues (Drinkwater, Tully and Dornan 2008). Conflicting evidence is presented about females and feedback in the literature. Whilst some studies report that female students are more active in seeking out feedback (DeLima Thomas and Arnold 2011), others report that they are not encouraged to do so in training situations (Rose, Rukstalis and Schuckit 2005). Despite males being reported as less likely to seek feedback, Lee et al. (2009) note that males are more assertive in their language, and so this may account for the positive provision of feedback when they actually do engage in the process. This supports the positive findings regarding male registrars in this study. However, the factors that impacted on why more female students did not report a better feedback process need to be examined more closely in future studies. This could very well be in keeping with the present construct that supports the call for a 'decolonised' system - namely one that does not support a white, male, heterosexual dominated student body and graduate population. Such unpacking of the existing paradigm will facilitate a better understanding of the dynamics and inform the necessary corrective measures that need to be implemented.

With regard to the effect of language, we found that consultants who were first language English speakers gave better feedback about how to be a communicator and a collaborator. Since communication can be one of the most useful tools at a clinician's disposal, it is vital that registrars be well-trained in this skill (Brindley et al. 2014). Singh et al. (2013) report that the ability to communicate well is one of the most highly rated qualities of effective medical teachers. It can be inferred from the findings of this study that consultants proficient in English took greater pains to give feedback about communication, possibly to improve deficiencies that they observed in registrars who were second language English speakers. This conclusion was supported by these registrars, who reported more positively on the various elements that they received feedback about. Registrars noted the impact that this had on improving their development and interactions with patients. The reason for this could be attributed to the fact that consultants made great efforts to ensure that the 'message transmitted' to those registrars who were being instructed in a language that was not their home language was clearly 'received and understood'.

In terms of age, this study found that in consultants, age was positively correlated with 
provision of feedback. Older consultants reported providing better feedback overall. Both consultants and registrars in this study felt that feedback from a more senior, experienced, consultant held in high esteem carried more weight than a junior consultant who was less well respected. If one equates age with experience this would support the finding that older consultants gave better feedback. Older consultants have both professional and personal expertise and experience that can shape the feedback process (Rose, Rukstalis and Schuckit 2005). However, it has been found that academic trainees, who were less experienced, nonetheless gave more comprehensive feedback based on holistic principles as compared to consultants. This could have been due to their familiarity with the academic subject material (Fernando et al. 2008).

Registrars in the first year of training had an overall better experience of feedback as compared to more senior registrars. These results are surprising in that they differ from the maturational effect one would expect with year of discipline (Murdoch-Eaton 2012). Perhaps consultants believe that novices to training require more 'handholding', in keeping with the paradigm of the 'see one, do one, teach one' approach to training prevalent in medical schools, and so take greater pains in providing feedback to these novices. This approach would be counter-intuitive to developing clinical competence, as registrars closer to the end of their training and approaching independent practice require just as much, if not more, feedback. While consultants might think that older registrars who are more experienced require less feedback, therefore providing less, it might be that these registrars are more complacent and less likely to report more positively on their experiences. Senior registrars reported that they received intermittent feedback and the heavy clinical workload they had to bear impacted on the time they had for studying and to reflect on feedback (McQueen et al. 2016; Shrivastava, Shrivastava and Ramasamy 2014; Cantillon and Sargeant 2008).

The study findings showed that consultants of race groups other than African appear to be more affected by the race of the registrar in providing feedback than is the case with African consultants. Supervision of residents is a responsibility of faculty that, ideally, should occur in a non-partisan manner (Rose, Rukstalis and Schuckit 2005) and provision of feedback should not be dependent on race. This finding would support the hypothesis that race is a factor in effective supervision, with the novice being drawn to a consultant of the same race and vice versa (Rose, Rukstalis and Schuckit 2005; Daniel 2007). In addition, this supports the findings of other studies, that the barriers that students of colour experience in achieving academic success can be due to lack of support, in particular, when encountering insensitive consultants (Odom et al. 2007). It could be argued that consultants from other race groups were more cognisant of the race of the registrars because of sensitivities to being labelled racist, whereas 
African consultants did not share these same concerns and so were less at pains to be politically correct. Hence, regardless of the reasons, either favourable or not, for this perceived racial bias, measures should be implemented to ensure that the clinical teaching environment is a non-racial one. However, the study also found that consultants did try to remain unbiased and objective when providing feedback. This is encouraging and needs to be further supported in multicultural environments.

The apprenticeship model of clinical medical education implies that feedback should occur equally in all disciplines. This was not evident in the findings of this study. Registrars in Surgery reported statistically more significant scores regarding the quality of feedback provided by consultants. This may be attributed to the nature of the discipline. Surgery requires more extensive and immediate feedback, as well as facilitated feedback, which occurs in the operating theatres. All modalities of feedback - immediate, brief, informal and formal (Branch and Paranjape 2002; DeLima Thomas and Arnold 2011) - appeared to be incorporated, which may account for this finding. Registrars' comments supported the finding that feedback in the discipline was excellent. Despite these positive reports, it must be noted that these registrars also reported that feedback given did not encourage reflection, a key competence for lifelong, self-directed learning and that they would not use their consultants' techniques with their own students. Therefore, while the teaching in the department appeared to be excellent and result orientated, there also appeared to be potential flaws within the process that would warrant further investigation to make the overall process more holistic and comprehensive.

\section{CONCLUSION}

Relationships between demographics and certain important aspects of the provision of feedback were observed at this institution which can impact on the context in which feedback is given and received. The effects of race, particularly in relation to underrepresented minorities and previously disadvantaged groups, have been cited as a barrier to achieving academic and professional success. One way to overcome this is to ensure that these students are provided with adequate mentorship that ensures proper feedback processes. Within the proposed context of a 'decolonised' and 'deracialised' syllabus and taking into the account the equity, rather than the equality, of the different academic needs of such students, appropriate academic support programmes should be implemented that prepare and equip ethnically diverse students to provide care for equally diverse populations. Such a transformation of curricula would extend beyond just counting the numbers of white and black students and professors to meet targets. Garuba (2015) argues that 'decolonising' both undergraduate and postgraduate medical education would call for more than mere re-writing of content, but rather learning from prior 
lessons of transformation and building on existing foundations to incorporate new modalities of teaching, for example, the integration of traditional and herbal remedies into conventional evidence-based medicine (Zhang, Xue and Fong 2011). The advantage of such innovations would be to legitimise this traditional knowledge so that it is not lost to future generations, as well as serving to add on to the gold standard that has come from Western knowledge, improving its relevance to the local patient population, thereby contributing to how syllabi can be 'decolonised'.

Another important aspect these support programmes should address is the issue of language, and the medium of instruction, taking care to ensure that the message 'transmitted' is not lost in the 'reception' because of common misunderstandings. The perception that feedback is not being adequately provided, may be an erroneous one and more simply due to the fact that feedback is not recognised as such when it is given. Students need to be made more clearly aware that they are indeed receiving feedback, be it brief, informal or formal. This process needs to begin in their undergraduate years.

Gender discrimination still exists, even though there are more women entering the medical work force now than in the past, and can be seen in how female doctors perceive themselves and their roles. Female registrars should be empowered to ask for appropriate feedback and the consultants to provide it.

The factor of age and, hence, experience of consultants was positively correlated, in that older consultants were seen to provide better quality feedback. In-service education and training should be provided to ensure that both junior and senior consultants are good teachers, as well as competent clinicians, and are best able to provide the feedback required. These updated training programmes should enshrine ‘Best Practices' from those disciplines that are practising good feedback, and advocate for delivery within an acceptable framework, for example, as elaborated upon by Nicol and Macfarlane-Dick (2006), together with a clear, synthesized operational definition of feedback.

The conclusions and recommendations of this study thus support a more libertarian approach to the revised process of feedback as it is presently practised, where the consciousness of students is raised so that they are not only more critically engaged with their subject material as entrenched in the curriculum, but that they also lend their voices to the process. This would address how the concerns of students can most readily be heard. While academics may fear this involvement in the governance of the university, it would serve as a means to keep the misuse of power by academics in check, by allowing students a forum to voice legitimate grievances (Shay 2016). These changes should also encompass changes in admission and assessment criteria that are a reflection of present societal inequities. Hence, we move beyond token 
changes that 'decolonisation' alone may result in, into the 'disorienting dilemmas' that ultimately result in transformation (Mezirow 1997).

While the limitations of this study were the small sample size and single setting, making it difficult to generalise, the findings nonetheless have relevance for this university setting and other such multicultural settings. Future studies should focus on more in-depth interviews with individuals to explore further some of the sensitive race, gender and language issues highlighted in this study.

\section{ACKNOWLEDGEMENTS}

This publication was made possible by grant number: R24TW008863 from the Office of the US Global AIDS Coordinator and the US Department of Health and Human Services, National Institutes of Health (NIH OAR and NIH ORWH). Its contents are solely the responsibility of the authors and do not necessarily represent the official views of the US government. Thanks are due to Dr Moise Muzigaba for help with statistical analysis and to the staff and students who participated in this study.

\section{REFERENCES}

Anderson, Peter A. M. 2012. Giving feedback on clinical skills: Are we starving our young? Journal of Graduate Medical Education 4(2): 154-158.

Archer, Julian C. 2010. State of the science in health professional education: Effective feedback. Medical Education 44(1): 101-108.

Badat, Saleem. 2016. Deciphering the meanings and explaining the South African higher education student protests of 2015-2016. Wits Institute for Social and Economic Research. http://wiser.wits.ac.za/system/files/documents/

Badat, Saleem. 2009. Theorising institutional change: Post-1994 South African higher education. Studies in Higher Education 34(4): 455-467.

Bagwandeen, Chauntelle I. and Veena S. Singaram. 2016a. Feedback as a means to improve clinical competencies: Consultants' perceptions of the quality of feedback given to registrars. African Journal of Health Professions Education 8(1): 113-116.

Bagwandeen, Chauntelle I. and Veena S. Singaram. 2016b. Feedback as a means to improve clinical competencies: Registrars' perceptions of the quality of feedback provided by consultants in an academic hospital setting. African Journal of Health Professions Education 8(1): 117-120.

Bing-You, Robert G. and Robert L. Trowbridge. 2009. Why medical educators may be failing at feedback. Journal of the American Medical Association 302(12): 1330-1331.

Boehler, Margaret L., David A. Rogers, Cathy J. Schwind, Ruth Mayforth, Jacquelyn Quin, Reed G. Williams and Gary Dunnington. 2006. An investigation of medical student reactions to feedback: a randomised controlled trial. Medical Education 40(8): 746-749.

Branch Jr., William T. and Anuradha Paranjape. 2002. Feedback and reflection: Teaching methods for clinical settings. Academic Medicine 77(12): 1185-1188.

Brindley, Peter G., Katherine E. Smith, Pierre Cardinal and Francois LeBlanc. 2014. Improving medical communication: Skills for a complex (and multilingual) clinical world. Canadian Respiratory Journal 21(2): 89-91. 
Busari, Jamiu O., Nielske M. Weggelaar, Andrieke C. Knottnerus, Petra-Marie Greidanus and Albert J. J. A. Scherpbier. 2005. How medical residents perceive the quality of supervision provided by attending doctors in the clinical setting. Medical Education 39(7): 696-703.

Cantillon, Peter and Joan Sargeant. 2009. Giving feedback in clinical settings. British Medical Journal 337(10_2): a1961-a1961.

Cornell University. 2010. A Strategic Plan 2010-2015. https://www.cornell.edu/strategicplan/ (Accessed 8 December 2016).

Creswell, John W. 2013. Research design: Qualitative, quantitative, and mixed methods approaches. New York: Sage Publications.

Daelmans, Hester E. M., Rene M. Overmeer, H. H. van der Hem-Stokroos, Albert J. J. A. Scherpbier, Coen D. A. Stehouwer and Cees P. M. van der Vleuten. 2006. In-training assessment: Qualitative study of effects on supervision and feedback in an undergraduate clinical rotation. Medical Education 40(1): 51-58.

Daniel, Carol Ann. 2007. Outsiders-within: Critical race theory, graduate education and barriers to professionalization. Journal of Sociology \& Social Welfare 34: 25-43.

Davis, Georgiann and Rachel Allison. 2013. Increasing representation, maintaining hierarchy: An assessment of gender and medical specialization. Social Thought and Research 32: 17-45.

Drinkwater, Jess, Mary Patricia Tully and Tim Dornan. 2008. The effect of gender on medical students' aspirations: A qualitative study. Medical Education 42(4): 420-426.

Ende, J. 1983. Feedback in clinical medical education. Journal of the American Medical Association 250(6): 777-781.

Ferguson, Eamonn, David James and Laura Madeley 2002. Factors associated with success in medical school: Systematic review of the literature. British Medical Journal 324(7343): 952-957.

Fernando, Nishan, Jennifer Cleland, Hamish McKenzie and Kevin Cassar. Identifying the factors that determine feedback given to undergraduate medical students following formative mini-CEX assessments. Medical Education 42(1): 89-95.

Garuba, Harry. 2015. What is an African curriculum? Mail \& Guardian 17.

Jussim, Lee, HsiuJu Yen and John R. Aiello. 1995. Self-consistency, self-enhancement, and accuracy in reactions to feedback. Journal of Experimental Social Psychology 31(4): 322-356.

Kilminster, Sue, Julia Downes, Brendan Gough, Deborah Murdoch-Eaton and Trudie Roberts. 2007. Women in medicine - is there a problem? A literature review of the changing gender composition, structures and occupational cultures in medicine. Medical Education 41(1): 39-49.

Kogan, Jennifer R., Lisa N. Conforti, Elizabeth C. Bernabeo, Steven J. Durning, Karen E. Hauer and Eric S. Holmboe. 2012. Faculty staff perceptions of feedback to residents after direct observation of clinical skills. Medical Education 46(2): 201-215.

Lee, Katherine B., Sanjeev N. Vaishnavi, Steven K. M. Lau and Dorothy A. Andriole. 2009. Cultural competency in medical education: Demographic differences associated with medical student communication styles and clinical clerkship feedback. Journal of the National Medical Association 101(2): 116-126.

McQueen, Sydney A., Bradley Petrisor, Mohit Bhandari, Christine Fahim, Victoria McKinnon and Ranil R. Sonnadara. 2016. Examining the barriers to meaningful assessment and feedback in medical training. The American Journal of Surgery 211(2): 464-475.

Mezirow, Jack. 1997. Transformative learning: Theory to practice. New Directions for Adult and Continuing Education 74: 5-12.

Murdoch-Eaton, Deborah and Joan Sargeant. 2012. Maturational differences in undergraduate medical students’ perceptions about feedback. Medical Education 46(7): 711-721.

Murdoch-Eaton, Deborah. 2012. Feedback: The complexity of self-perception and the transition from 'transmit' to 'received and understood'. Medical Education 46(6): 538-540. 
Nelson, Mary Lee and Elizabeth L. Holloway. 1990. Relation of gender to power and involvement in supervision. Journal of Counselling Psychology 37(4): 473-481

Nicol, David J. and Debra Macfarlane-Dick. 2006. Formative assessment and self-regulated learning: A model and seven principles of good feedback practice. Studies in Higher Education 31(2): 199218.

Odom, Kara L., Laura Morgan Roberts, Rachel L. Johnson and Lisa A. Cooper. 2007. Exploring obstacles to and opportunities for professional success among ethnic minority medical students. Academic Medicine 82(2): 146-153.

Ramani, Subha and Sharon K. Krackov. 2012. Twelve tips for giving feedback effectively in the clinical environment. Medical Teacher 34(10): 787-791.

Redden, Elizabeth. 2015. In South Africa, push continues for free tuition and adequate support. Inside Higher Education. https://www.insidehighered.com/news/2015/11/18/south-africa-pushcontinues-free-tuition-and-adequate-support

Rose, Gail L., Margaret R. Rukstalis and Marc A. Schuckit. 2005. Informal mentoring between faculty and medical students. Academic Medicine 80(4): 344-348.

Ruggs, Enrica and Michelle Hebl. 2012. Literature overview: Diversity, inclusion, and cultural awareness for classroom and outreach education. Apply research to practice (ARP) resources. https://www.engr.psu.edu/awe/ARPAbstracts/DiversityInclusion/ARP_DiversityInclusionCultur alAwareness_Overview.pdf

Sender Liberman, A., Moishe Liberman, Yvonne Steinert, Peter McLeod and Sarkis Meterissian. 2005. Surgery residents and attending surgeons have different perceptions of feedback. Medical Teacher 27(5): 470-472.

Shay, Suellen and Tai Peseta. 2016. A socially just curriculum reform agenda. Teaching in Higher Education 21(4): 361-366.

Shrivastava, Saurabh, Prateek Shrivastava and Jegadeesh Ramasamy. 2014. Effective feedback: An indispensable tool for improvement in quality of medical education. Journal of Pedagogic Development 4(1): 12-20

Sinclair, Hazel K. and Jennifer A. Cleland. 2007. Undergraduate medical students: Who seeks formative feedback? Medical Education 41(6): 580-582.

Singh, Simerjit, Dinker R. Pai, Nirmal K. Sinha, Avneet Kaur, Htoo Htoo Kyaw Soe and Ankur Barua. 2013. Qualities of an effective teacher: What do medical teachers think? BMC Medical Education 13(1): 1.

Thomas, Jane DeLima and Robert M. Arnold. 2011. Giving feedback. Journal of Palliative Medicine 14(2): 233-239.

Van de Ridder, J. M., Karel M. Stokking, William C. McGaghie and Olle Th J. Ten Cate. 2008. What is feedback in clinical education? Medical Education 42(2): 189-197.

Wittich, Christopher M., Karen F. Mauck, Jayawant N. Mandrekar, Karol A. Gluth, Colin P. West, Scott C. Litin and Thomas J. Beckman. 2012. Improving participant feedback to continuing medical education presenters in internal medicine: A mixed-methods study. Journal of General Internal Medicine 27(4): 425-431.

Woolf, Katherine, Henry W. W. Potts and I. C. McManus. 2011. Ethnicity and academic performance in UK trained doctors and medical students: Systematic review and meta-analysis. British Medical Journal 342: 135-159

Zehra, Tabassum, Muhammad Tariq, Afaq Motiwala, Syeda Kauser Ali and John Boulet. 2015. Challenges of providing timely feedback to residents: Faculty perspectives. Journal of Pakistan Medical Association 65(10): 1069-1074.

Zhang, Anthony Lin, Charlie Changli Xue and Harry H. S. Fong. 2011. Integration of herbal medicine into evidence-based clinical practice. In Herbal medicine: Biomolecular and clinical aspects, ed. Iris F. F. Benzie and Sissi Wachtel-Galor, Chapter 22. $2^{\text {nd }}$ Edition. Boca Raton, CRC Press. 